\title{
Presence of a soluble form of acetylcholinesterase in human ocular fluids
}

\author{
Margaret E Appleyard, Brendan McDonald, Larry Benjamin
}

\begin{abstract}
Samples of ocular fluid obtained from normal persons at necropsy and during eye surgery have been assayed for the presence of acetylcholinesterase. Measurable levels could be detected in all samples examined, but levels of acetylcholinesterase in vitreous humour were consistently higher than those in aqueous humour, indicating a possible retinal origin. Polyacrylamide gel electrophoresis revealed that the enzyme of ocular fluid had the same mobility as that of acetylcholinesterase from cerebrospinal fluid. It is probable that acetylcholinesterase is secreted from neuronal structures in the retina into the ocular fluid in an analogous manner to the secretion of acetylcholinesterase from brain neurones into cerebrospinal fluid.
\end{abstract}

Several studies have demonstrated the secretion of acetylcholinesterase (AChE) from neurones within the mammalian central nervous system, ${ }^{1-}$ ${ }^{4}$ which may account for its presence in human cerebrospinal fluid (CSF) ${ }^{5}$ and in amniotic fluid in cases of neural tube defect. ${ }^{6}$ Indeed, animal studies have demonstrated increased levels of AChE in CSF following electrical and drug

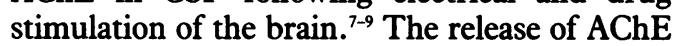
has also been demonstrated in the peripheral nervous system, for example from the phrenic nerve-diaphragm preparation, ${ }^{10}$ sympathetic ganglia, ${ }^{11}$ and nerve plexuses of the ileum. ${ }^{12}$ The last may explain its presence in human amniotic fluid in cases of fetal exomphalos. ${ }^{13}$

Appreciable levels of AChE are present in University Department of Pharmacology, South Parks Road, Oxford OX1 3QT

MAppleyard

MRC Unit of

Neuroanatomical

Pharmacology, South

Parks Road, Oxford OX

30T, and Nuffield

Department of Pathology

and Bacteriology, John

Radcliffe Hospital,

Headington, Oxford OX3

9DU

B McDonald

Oxford Eye Hospital and Nuffield Laboratory of Ophthalmology, Walton Street, Oxford OX2 6AW L Benjamin

Correspondence to:

Correspondence to:

Dr M E Appleyard,
Department of Physiology

Repartment of Physiology,

Royal Free Hospital Scho

Medicine, Rowland Hill

Street, London NW3 $2 \mathrm{PF}$ 26 October 1990 ocular tissues such as the amacrine cells of the retina $^{14}$ and the nerve plexuses of the iris. ${ }^{15}$ Hence any secretion of $\mathrm{AChE}$ from such tissues would be expected to result in detectable levels of enzymatic activity in the fluids of the eye by analogy with the situation in CSF. Although there are some reports from the 1940s of cholinesterase activity in ocular fluids of various mamalian species, ${ }^{16}$ no attempt was made to distinguish between $\mathrm{AChE}$ and butyrylcholinesterase (BuChE) activities. Furthermore no attempts have been made to confirm these reports by spectrophotometric assay methods.

In an attempt to demonstrate the possible secretion of $\mathrm{AChE}$ from neuronal structures within the human eye we have therefore examined human ocular fluids for the presence of AChE and $\mathrm{BuChE}$ activities. We have also compared, by polyacrylamide gel electrophoresis, the enzyme forms present with that present in human CSF, which is thought to derive, by secretion, from neuronal structures of the central nervous system.

\section{Materials and methods \\ COLLECTION OF OCULAR FLUIDS}

\section{At necropsy}

Ocular fluids were collected at necropsy from persons dying of non-neurological conditions and in whom a past history of eye disease was absent. The eyelids were retracted by hand, and aqueous humour was collected from the anterior chamber by direct puncture through the cornea with a $25 \mathrm{G}$ needle attached to a sterile $1 \mathrm{ml}$ syringe followed by gentle aspiration of the contents. Similarly the vitreous humour was collected from the vitreous cavity by direct puncture through the sclera, posterior to the ciliary body (through pars plana), with a $27 \mathrm{G}$ needle attached to a sterile $2 \mathrm{ml}$ syringe. Any samples in which there was discolouration of the fluid suggesting possible contamination by either iris or retina were discarded. The normal cosmetic appearance of the eye was reconstituted by injecting a similar volume of saline back into the eye chambers.

The ocular fluids were transferred from the syringe to $1.5 \mathrm{ml}$ microfuge tubes and centrifuged for 10 minutes at $12000 \mathrm{~g}$ to sediment particulate matter. The supernatant was then gently aspirated off into another microfuge tube, labelled, snap frozen in liquid nitrogen, and stored at $-70^{\circ} \mathrm{C}$.

Initially, in order to provide adequate volumes for repeated assays, the vitreous and aqueous humours from one patient were pooled (to give a ratio vitreous:aqueous of $10: 1$ ). In later experiments the two types of humour were handled separately.

\section{During eye surgery}

Aqueous humours were collected during eye surgery (for cataract removal) from patients with no history of other eye diseases or neurological disease. The skin of the eyelids was prepared for surgery with iodine solution, then dried. The lids were then held open with a speculum and an initial corneal groove made with a diamond knife. A $27 \mathrm{G}$ sterile needle was passed into the anterior chamber via the corneal groove and approximately $0 \cdot 1-0.15 \mathrm{ml}$ of aqueous humour removed into a $1 \mathrm{ml}$ syringe. This was transferred straight into a sterile microfuge tube and frozen at $-20^{\circ} \mathrm{C}$ within 1 hour.

In six of the patients the surgical procedures were carried out under local anaesthesia (xylocaine), and samples were taken within 10 minutes of retrobulbar injection. The remainder received a general anaesthetic, samples being taken 10-15 minutes after induction of anaesthesia. All patients received premedication 
consisting of phenylephrine and cyclopentolate eyedrops.

\section{COLLECTION OF CEREBROSPINAL FLUID AT NECROPSY}

After opening of the cranial cavity CSF was aspirated from the level of the basal cistern with the exposed brain still in situ. The CSF samples were then centrifuged at $3000 \mathrm{~g}$ for 30 minutes at $4^{\circ} \mathrm{C}$, and the supernatent was divided into aliquots, snap frozen, and stored at $-70^{\circ} \mathrm{C}$ for up to one year.

\section{BIOCHEMICAL ANALYSIS}

Cholinesterase activities were measured by a microversion of the method of Ellman et al, ${ }^{17}$ with microtitre plates. Acetylthiocholine was used as substrate at a concentration of $1.0 \mathrm{mM}$, which is optimal for AChE, but suboptimal for BuChE. The assay was performed at $25^{\circ} \mathrm{C}$ in $0.05 \mathrm{M} \mathrm{Na} / \mathrm{K}$ phosphate buffer, $\mathrm{pH} 7.0$ con-

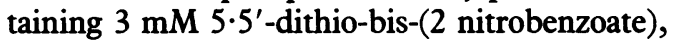
in a total volume of $100 \mu \mathrm{l}$. The rate of hydrolysis of acetylthiocholine was monitored by measurement of absorbances at $410 \mathrm{~nm}$ with a Titertek multiscan microplate reader. A calibration curve was constructed with purified electric eel AChE (Sigma) that had previously been assayed by a stopped assay version of the conventional Ellman assay $^{18}$ such that $1 \mathrm{mU}$ cholinesterase activity corresponded to $1 \mathrm{nmol}$ acetylthiocholine hydrolysed per minute at $30^{\circ} \mathrm{C}$, pH $7 \cdot 0$. The assay was linear up to an absorbance reading of 2.0. AChE and BuChE activities were distinguished by means of the specific AChE inhibitor BW 284c51 (1.5 $\mu \mathrm{M})$. All assays were performed in triplicate, with good agreement between them.

Estimation of the protein content of the ocular fluids was performed by a micro version of the Biorad dye-binding assay. ${ }^{19}$

Samples of ocular fluids and CSF were analysed by polyacrylamide gel electrophoresis. The gels were incubated with acetylthiocholine to reveal brands of cholinesterase activity, ${ }^{20}$ with $\mathrm{BW}$ $284 c 51$ to distinguish between $\mathrm{AChE}$ and BuChE.

\section{STATISTICS}

All values are reported as mean with SEM. Differences between activities of aqueous, vitreous, and mixed ocular fluids were tested for statistical significance by Wilcoxon's signed rank test, or the Mann-Whitney U test, as appropriate. Correlations between the activities of $\mathrm{AChE}$ and the age of the patient at death, or the postmortem delay, were analysed by the Spearman rank correlation test. In all cases a value of $\mathrm{p}<0.05$ was taken to indicate statistical significance.

\section{Results}

Cholinesterase activity was detectable in all samples of ocular fluid examined, with acetylthiocholine as substrate. Most of this activity was inhibited by the specific AChE inhibitor BW
Table 1 Cholinesterase activities (SEM in parentheses) of different types of human ocular fluid obtained either post mortem or at eye surgery

\begin{tabular}{|c|c|c|c|}
\hline Ocular fluid & $\begin{array}{l}\text { Total ChE } \\
\text { activity }\end{array}$ & $\begin{array}{l}\text { AChE } \\
\text { activity }\end{array}$ & $\% A C h E$ \\
\hline $\begin{array}{l}\text { PM pooled fluids } \\
(\mathrm{n}=18)\end{array}$ & $31 \cdot 4(3 \cdot 8)$ & $23 \cdot 9(3 \cdot 3)$ & $75.4(2.9)$ \\
\hline $\begin{array}{l}\text { PM vitreous humour } \\
(\mathrm{n}=5)\end{array}$ & $20 \cdot 6(2 \cdot 0)$ & $14 \cdot 7(1 \cdot 5) \mathrm{NS}$ & $70 \cdot 7(1 \cdot 9)$ \\
\hline $\begin{array}{l}\text { PM aqueous humour } \\
(\mathrm{n}=5)\end{array}$ & $22 \cdot 6(1 \cdot 2)$ & $11 \cdot 4(1 \cdot 2) \mathrm{NS}$ & $51 \cdot 3(5 \cdot 2)$ \\
\hline $\begin{array}{r}\text { Surgical aqueous } \\
\text { humour }(n=8)\end{array}$ & $3.9(0.3)$ & $2 \cdot 6(0 \cdot 5)^{\star}$ & $79 \cdot 4(7 \cdot 2)$ \\
\hline
\end{tabular}

$\mathrm{PM}=$ post mortem. Acetylcholinesterase activities are given in $\mathrm{mU}$ per $\mathrm{ml} \mathrm{CSF}$. ^Significantly different from level in mixed ocular fluids obtained at necropsy (Mann-Whitney U test, $\mathrm{p}<0 \cdot 001$ ).

$284 c 51$, indicating that the majority of cholinesterase activity was attributable to $\mathrm{AChE}$, while levels of non-specific cholinesterase activity were comparatively low. The AChE activities of total ocular fluid obtained at necropsy were much higher than those detected in aqueous humour obtained during surgery from living patients (Table 1). When aqueous and vitreous humours were obtained separately at necropsy, the $\mathrm{AChE}$ activity of the vitreous humour was significantly higher ( $p<0.05$ by Wilcoxon signed rank test)
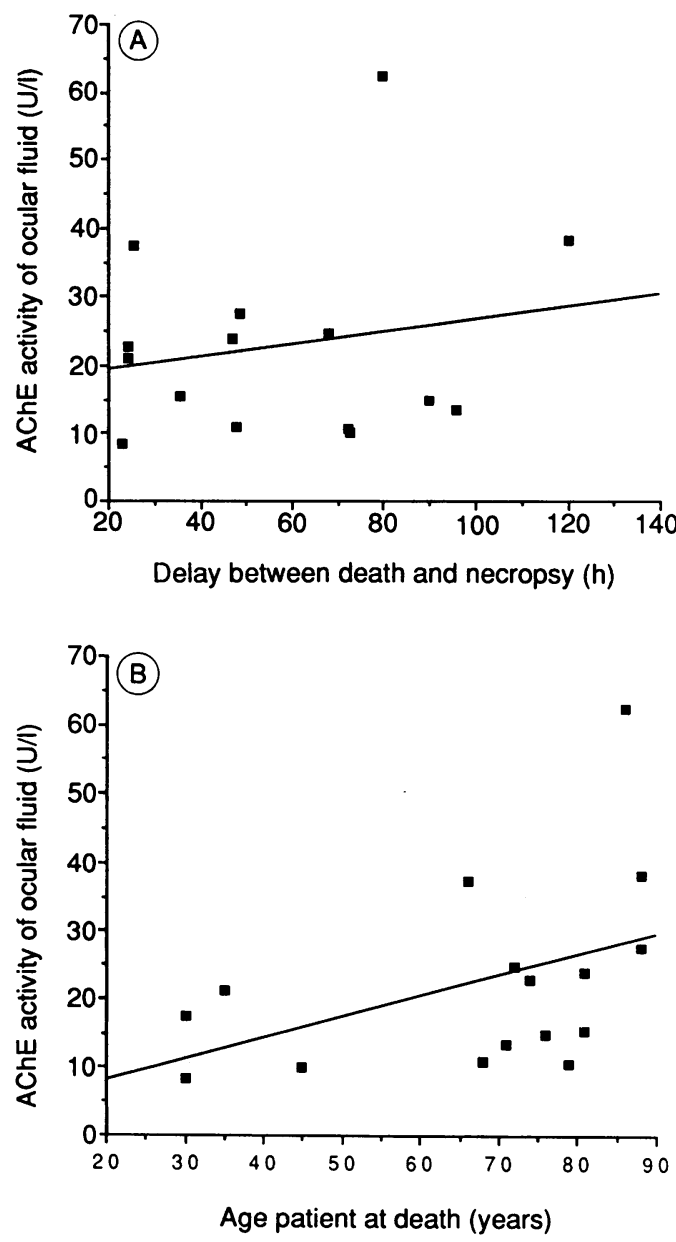

Figure 1 Graphs to show the relationship between AChE activity of ocular fluid obtained at necropsy and $(A)$ the delay between death and necropsy, $(B)$ the age of the patient at death. In each case the line shown is the line of best fit as determined by linear regression using the method of least squares. Spearman rank correlation coefficients indicated that there was no significant correlation between AChE activity and post-mortem delay, but AChE activity was significantly correlated with age. 


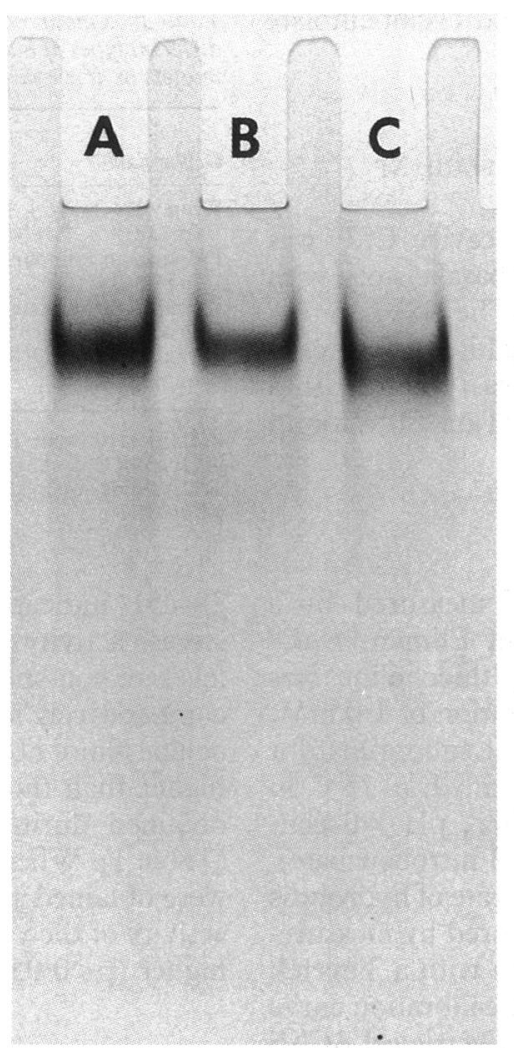

Figure 2 Polyacrylamide gel of ocular fluid and cerebrospinal fluid stained to reveal cholinesterase activity. The samples were applied at the top and the direction of migration was towards the anode. Track $A$ contained ocular fluid obtained at necropsy; track B contained cisternal cerebrospinal fluid obtained at necropsy from the same patient; track $C$ contained a mixture of ocular fluid and cerebrospinal fluid. A similar gel stained in the presence of $B W 284 c 51$ had no detectable staining.

than that of aqueous humour from the same eye (Table 1).

There was no significant correlation between $\mathrm{AChE}$ activity of the total ocular fluid obtained at necropsy and the delay between death and necropsy, the Spearman rank correlation coefficient being $0 \cdot 181(n=17)$ (Fig 1A). However, there was a significant correlation $(p<0.01)$ between AChE activity of total ocular fluid and the age of the patient at death, with a Spearman rank correlation coefficient of $0.542(n=16)$ (Fig 1B).

Polyacrylamide gel electrophoresis of total ocular fluid revealed one band of $\mathrm{AChE}$ activity with a similar mobility to that of AChE in CSF obtained from the cisterna magna of the same patient. Indeed, only one band of $\mathrm{AChE}$ activity could be detected in a mixture of ocular fluid and CSF (Fig 2).

Comparison of the cholinesterase activities of total ocular fluid and cisternal CSF obtained at necropsy indicates that ocular fluid contains slightly higher levels of AChE activity, but considerably lower levels of BuChE activity, than cisternal CSF (Table 2 ). The specific activity of AChE in ocular fluid was markedly higher than that of cisternal CSF owing to the much lower levels of protein present (Table 2).

\section{Discussion}

These results show that $\mathrm{AChE}$ is present in human ocular fluids in appreciable levels while
Table 2 Comparison of cholinesterase activities (SEM in parentheses) of ocular fluid and cisternal CSF obtained post mortem from the same patients

\begin{tabular}{lll}
\hline Enzyme & Total ocular fluid & Cisternal CSF \\
\hline AChE & $23 \cdot 9(3 \cdot 3)$ & $21 \cdot 0(4 \cdot 2)$ \\
BuChE & $13 \cdot 8(2 \cdot 2)$ & $36 \cdot 4(13 \cdot 9)$ \\
Protein & $0 \cdot 84(0 \cdot 16)$ & $3 \cdot 7(0 \cdot 8)$ \\
Specific activity AChE & $37 \cdot 5(5 \cdot 9)$ & $3 \cdot 7(0 \cdot 9)$ \\
\hline
\end{tabular}

Cholinesterase activities are given in $\mathrm{mU}$ and protein contents are given in $\mathrm{mg}$ per $\mathrm{ml}(=\mathrm{g} / \mathrm{l}) \mathrm{CSF}$. Specific activities $\mathrm{AChE}$ are given as $\mathrm{mU}$ AChE activity per $\mathrm{mg}$ protein.

levels of BuChE are very low. The levels of AChE detectable in total ocular fluids obtained at necropsy are comparable to those found in CSF also obtained at necropsy from the same patient, though they are slightly higher.

The levels of AChE detectable in total ocular fluids obtained at necropsy are markedly higher than those present in aqueous humour obtained from living patients during eye surgery. This could be explained if the majority of $\mathrm{AChE}$ activity observed in total ocular fluid at necropsy derived from the vitreous humour rather than the aqueous humour. The lower levels of AChE activity observed in the aqueous humour compared with the levels in vitreous humour in the few patients from whom the two fluids were collected separately would appear to support this explanation. The results of previous studies in the 1940s also suggest that most of the cholinesterase activity in ocular fluids is confined to the vitreous humours. ${ }^{16}$ This is not surprising, since it is the vitreous humour and not the aqueous humour which is in contact with the retina, where the majority of AChE-containing cells of the eye are situated. It is likely that some equilibration of the two pools of fluid would have occurred during the time between death and necropsy thus accounting for the higher levels of $\mathrm{AChE}$ found in aqueous humour obtained at necropsy compared with the levels found in living patients.

An alternative explanation for higher levels of AChE observed at necropsy is that they are a post-mortem artefact due to the non-specific release of AChE from the tissues of the eye during the period between death and collection at necropsy. However, if this were the case, the level of AChE activity present in the fluid samples should correlate with the time delay between death and necropsy. As these two parameters were not correlated this explanation is unlikely.

The drug regimens of the patients could also contribute to these differences in AChE activity, since various drugs have been shown to affect the secretion of $\mathrm{AChE}$ from the central nervous system into CSF ${ }^{8}$ Certainly all the surgical patients received the muscarinic antagonist cyclopentolate topically during premedication, and such drugs have been shown to decrease the secretion of $\mathrm{AChE}$ into $\mathrm{CSF}^{9}$ and from the hippocampus. ${ }^{2}$ It is therefore possible that this drug also decreases secretion of AChE from cholinergic tissues of the eye such as lens, ciliary body, and iris, and therefore causes lower levels of $\mathrm{AChE}$ in the aqueous humour.

The AChE activity of total ocular fluid obtained at necropsy was found to increase with 
the age of the patient, such that the two were significantly correlated. Previous studies have found a similar effect of age on the $\mathrm{AChE}$ activity of CSF. ${ }^{21} 22$

Polyacrylamide gel electrophoresis indicates that the AChE present in ocular fluid has a similar mobility to that of human CSF; indeed the two activities comigrate in a mixture of the two fluids. The form of $\mathrm{AChE}$ present in ocular fluids is therefore likely to be the same as that in CSF. Since the AChE activity in CSF is believed to result from secretion of AChE from the surrounding neuronal tissues, it is also likely that the AChE found in ocular fluids is a result of secretion from the AChE-containing tissues of the eye. It would certainly be worthwhile to investigate, by direct methods, whether basal and evoked secretion of $\mathrm{AChE}$ from retinal tissues does occur under normal physiological conditions.

In vitro studies have previously failed to demonstrate any secretion of AChE from the iris, ${ }^{3}$ which contains appreciable amounts of $\mathrm{AChE}$ in nerve plexuses. The results of the present study suggest that secretion of $\mathrm{AChE}$ from the tissues of the iris is negligible, at least in humans, since aqueous humour which is in close contact with the iris contains little $\mathrm{AChE}$ activity when collected during life (though this could be an effect of cyclopentolate administration).

The functional significance of any secretion of AChE from retinal cells is at present unclear. However, several studies now suggest that secreted AchE may have modulatory effects on the excitability of neurones in the central nervous system..$^{23}$ It is possible that AChE could have a similar role in the retina.

B McDonald held a Wellcome Research training fellowship in pathology. M E Appleyard held a Tilleard-Cole research fellowship at Worcester College. The work was supported by grants from the Grand Charity and Bristol-Meyers-Squibb Co. We would like to
thank Walter Zawilinski and Paul Butler for technical assistance thank Walter Zawiling
during necropsies.

1 Greenfield SA, Cheramy A, Leviel V, et al. In vivo release of acetylcholinesterase in cat substantia nigra and caudate acetylcholinesterase in cat substant

2 Appleyard ME, Smith AD. Spontaneous and carbacholevoked in vivo secretion of acetylcholinesterase from the hippocampus of the rat. Neurochem Int 1987; 11: 397-406.

3 De Sarno P, Giacobini E, Downen M. Release of acetylcholinesterase from the caudate nucleus of the rat. $\mathcal{F}$ Neurosci Res 1987; 18: 578-90.

4 Appleyard ME, Vercher JL, Greenfield SA. Release of acetylcholinesterase from the guinea-pig cerebellum in vivo. Neuroscience 1988; 25: 133-8.

5 Tower DB, McEachern D. Acetylcholine and neuronal activity: II. Acetylcholine and cholinesterase activity in the cerebrospinal fluid of patients with epilepsy. Can $\mathcal{F} \operatorname{Res} E$ 1949; 27: 120-31.

6 Smith AD, Wald NJ, Cuckle HS, Stirratt GM, Bobrow M, Langerkrantz H. Amniotic fluid acetylcholinesterase as a possible diagnostic test for neural tube defects in early pregnancy. Lancet 1979; i: 685-8.

7 Bareggi SR, Giacobini E. Acetylcholinesterase activity in ventricular and cisternal CSF of dogs. 7 Neurosci Res 1978 . 3: 335-9.

8 Greenfield SA, Chubb IW, Smith AD. The effect of chlorpromazine on the concentration of acetylcholinesterase activity in the cerebrospinal fluid of rabbits. Neuropharmactivity in the cerebrospinal $1979 ; 18: 127-32$.

9 Vogt $M$, Smith AD, Fuenmayor LD. Factors influencing the cholinesterases of cerebrospinal fluid in the anaesthetised cat. Neuroscience 1984; 12: 797-995.

10 Skau KA, Brimijon S. Release of acetylcholinesterase from rat hemidiaphragm preparations stimulated through the phrenic nerve. Nature 1978; 275: $224-6$.

11 Gisiger V, Vigny M. A specific form of acetylcholinesterase is secreted by rat sympathetic ganglia. FEBS Lett 1977; 84: 253-6.

12 Appleyard ME, Smith AD. Secretion of acetylcholinesterase and butyrylcholinesterase from the guinea-pig isolated ileum. Br f Pharmacol 1989; 97: 490-8.

13 Wald NJ, Cuckle HS, Barlow RD, et al. Early antenatal diagnosis of exomphalos. Lancet 1980; i 1368-9.

14 Hutchins JB, Hollyfield JG. Acetylcholinesterase in the human retina. Brain Res 1987; 400: 300-11.

15 Mattio TG. Richardson JS, Giacobini E. Effects of DFP on iridic metabolism and release of acetylcholine and on pupillary function in the rat. Neuropharmacology 1984; 23: 1207-14.

16 De Roeth A. Cholinesterase activity in ocular tissues and fluids. Arch Ophthalmol 1950; 43: 1004-25.

17 Ellman GL, Courtney DK, Andres V, Featherstone RM. A new and rapid colorimetric determination of acetylcholinesterase activity. Biochem Pharmacol 1961; 7: 88-95.

18 Chubb IW, Smith AD. Release of acetylcholinesterase into the perfusate from the ox adrenal gland. Proc $R$ Soc $B$ 1975; 191 : 263-9

19 Bradford MM. A rapid and sensitive method for the quantification of microgram quantities of protein utilising the
principle of protein-dye binding. Anal Biochem 1976; 72: principle

20 Chubb IW, Smith AD. Isoenzymes of soluble nd membranebound acetylcholinesterase in bovine splanchnic nerve and adrenal medulla. Proc $R$ Soc $B$ 1975; 191: 245-61.

21 Tune L, Gucker S, Folstein M, Oshida L, Coyle JT. Cerebrospinal fluid acetylcholinesterase activity in senile dementia of the Alzheimer type. Ann Neurol 1985; 17: 46-8.

22 Appleyard ME, Smith AD, Berman P, et al. Cholinesterase activities in cerebrospinal fluid of patients with senile dementia of the Alzheimer type. Brain 1987; 110: 1309-22.

23 Greenfield SA, Jack JJB, Last ATJ, French M. An electrophysiological action of acetylcholinesterase independent of physiological action of acetylcholinesterase indeper

24 Appleyard ME, Jahnsen $H$. Non-cholinergic effects of acetylcholinesterase upon the membrane properties of mammalian cerebellar Purkinje cells. Eur $\mathcal{Y}$ Neurosci 1989; suppl 2: 129. 